Case report

\title{
Huge gastric bezoar caused by honeycomb, an unusual complication of health faddism: a case report Panagiotis Katsinelos ${ }^{1}$, Ioannis Pilpilidis ${ }^{1}$, Grigoris Chatzimavroudis ${ }^{1}{ }^{*}$, Taxiarchis Katsinelos ${ }^{1}$, Georgia Lazaraki ${ }^{1}$, Kostas Fasoulas ${ }^{1}$, Christos Zavos ${ }^{2}$ and Jannis Kountouras ${ }^{2}$
}

\author{
Address: ${ }^{1}$ Department of Endoscopy and Motility Unit, "G.Gennimatas" General Hospital, Ethnikis Aminis 41, Thessaloniki, 54635, Greece and \\ ${ }^{2}$ Department of Gastroenterology, Second Department of Internal Medicine, Ippokration Hospital, Aristotle University of Thessaloniki, \\ Konstantinoupoleos 49, Thessaloniki, 54624, Greece \\ Email: PK - pk@yahoo.gr; IP - ip@yahoo.gr; GC* - gchatzimav@yahoo.gr; TK - tk@yahoo.gr; GL - gl@yahoo.gr; KF - kf@yahoo.gr; \\ CZ - czavos@hotmail.com; JK - jannis@med.auth.gr \\ * Corresponding author \\ Published: 15 May 2009 \\ Cases Journal 2009, 2:7077 doi: 10.1186/1757-1626-2-7077 \\ This article is available from: http://casesjournal.com/casesjournal/article/view/7077 \\ (C) 2009 Katsinelos et al; licensee Cases Network Ltd. \\ This is an Open Access article distributed under the terms of the Creative Commons Attribution License (http://creativecommons.org/licenses/by/3.0), \\ which permits unrestricted use, distribution, and reproduction in any medium, provided the original work is properly cited.
}

\begin{abstract}
We report a young healthy woman, who believed that the consumption of large amounts of honeycomb would lead to good health and who finally developed a huge gastric bezoar of hard consistency. The conventional endoscopic techniques failed to manage the bezoar. Using the combination of injection of hydrogen peroxide $3 \%$ solution inside the bezoar to induce disintegration and a special designed needle-knife sphincterotome (bezotome) we managed to remove the bezoar in fragments. To the best of our knowledge this is the first reported bezoar caused by honeycomb.
\end{abstract}

\section{Introduction}

Bezoars are foreign bodies found mainly in the stomach, which are composed of plant and vegetables (phytobezoars), persimmous (diospyrobezoars), hair (trichobezoars), milk (lactobezoars) or other bezoars [1]. Their management includes a wide spectrum of treatment options, from conservative treatment to surgery or endoscopic intervention $[1,2]$.

We describe the first case of a huge bezoar of very hard consistency, made from honeycomb, which required sophisticated endoscopic techniques for its removal.

\section{Case Presentation}

A 44-year-old Greek woman was referred to our department for endoscopic treatment of a huge gastric bezoar. Past medical history of the patient revealed daily consumption of large quantities of honeycomb during the last 2 months, because she believed that the honeycomb might have beneficial effect on the irritable bowel syndrome and on her health in general. Physical examination and laboratory data were unremarkable. During last ten days, she presented episodes of epigastric pain associated with nausea, especially after eating. Despite the initiation of treatment with proton pump 
inhibitors, the symptoms were not relieved. Upper endoscopy performed by a private gastroenterologist disclosed a yellow coloured huge bezoar, very hard to touch with forceps.

We performed the intervention with propofol administration to achieve a well-sedated patient. Endoscopic examination of stomach confirmed previous findings (Figure 1). We tried to fragment the bezoar with the use of snares and baskets but only superficial pieces were removed, leaving the bezoar practically intact. Trying to disintegrate the bezoar, we injected, via a variceal needle, inside it $100 \mathrm{ml}$ of hydrogen peroxide $\left(\mathrm{H}_{2} \mathrm{O}_{2}\right) 3 \%$ solution. 24 hours later, we repeated the endoscopy and using a modified needle-knife (length of cutting wire $20 \mathrm{~mm}$ versus $5 \mathrm{~mm}$ of a conventional needle-knife) we performed fragmentation and removal of the bezoar.

\section{Discussion}

The majority of gastric bezoars occur in patients who have undergone previous gastric surgery [2]. Loss of antral and pyloric function because of partial gastric resection and reduced gastric motility following vagotomy are major causes of gastric stasis $[1,2]$. Other predisposing conditions are impaired mastication, gastroparesis/hypochlorhydria, anatomic abnormalities such as diverticula or gastric outlet obstruction, inadequate fluid intake leading to dehydration and inspissation of enteric feeding formula $[1,2]$.



Figure I. A huge honeycomb-bezoar occupying the gastric lumen.
The clinical presentation of gastric bezoars includes abdominal pain (70\%), vomiting and nausea (64\%), and early satiety [1-4]. Obstructive symptoms may be intermittent, owing to a ball valve mechanism of obstruction [2]. In some cases the initial presentation may be that of iron deficiency anemia The diagnosis is made by abdominal ultrasound, computed tomography, barium meal examination or endoscopy [5].

Current management includes conservative treatment (meaning waiting for them to disintegrate and pass spontaneously) if the bezoars are small, which however carries the risk of small bowel obstruction in patients who have had gastrectomy; medical treatment with enzymes and prokinetic agents [6]; endoscopic management; and surgical removal. Huge hard bezoars usually require mechanical treatment [3]. Operation is necessary if endoscopic removal fails. Endoscopic management includes enzymatic dissolution by injecting cellulase, use of a water jet, a drill device, tripod forceps, polypectomy snare plus diathermy, Dormia basket, mechanical lithotriptor, or neodymium-yttrium-aluminium-garnet $(\mathrm{Nd}$ : YAG) [1-3].

Our case is very intriguing because the consumption of honeycomb has not been reported to lead to gastric bezoar formation. Moreover, the honeycomb-bezoar was very hard to be cut with a snare or basket. We injected inside the bezoar, $100 \mathrm{ml} \mathrm{H}_{2} \mathrm{O}_{2} 3 \%$ solution via a variceal needle. The aim of this injection was the contribution of $\mathrm{H}_{2} \mathrm{O}_{2}$ in disintegration of the bezoar. The endoscopy was repeated 24 hours later. Using a modified needle-knife (bezotome) and monopolar cutting current we were able to incise the bezoar into fragments, which were easily retrieved.

\section{Conclusion}

Our case shows that even a huge solid bezoar with hard consistency does not need to be operated on. By using sophisticated endoscopic techniques the fragmentation and removal of such bezoars is feasible.

\section{Consent}

Written informed consent was obtained from the patient for publication of this case report and accompanying image. A copy of the written consent is available for review by the Editor-in-Chief of this journal.

\section{Competing interests}

The authors declare that they have no competing interests.

\section{Authors' contribution}

PK performed the endoscopy and was contributor in writing the manuscript. IP, GC, and $\mathrm{CZ}$ analyzed and interpreted the patient data and were contributors in 
writing the manuscript. TK, GL and KF reviewed the relative literature. JK was major contributor in revising the manuscript critically for important intellectual content. All authors read and approved the final manuscript.

\section{References}

I. Lee J: Bezoars and foreign bodies of the stomach. Gastrointest Endosc Clin N Am 1996, 6:605-6I9.

2. Andrus $\mathrm{CH}$, Ponsky JL: Bezoars: classification, pathophysiology and treatment. Am J Gastroenterol 1988, 83:476-478.

3. Erzurumlu K, Malazgirt Z, Bektas A, Dervisoglu A, Polat C, Senyurek G, Yetim I, Ozkan K: Gastrointestinal bezoars a retrospective analysis of $\mathbf{3 4}$ cases. World J Gastroenterol 2005, II:I8I3-18I7.

4. Wang YG, Seitz U, Li ZL, Soehendra N, Qiao XA: Endoscopic management of huge bezoars. Endoscopy 1998, 30:37I-374.

5. Ripolles T, Garcia-Aguayo J, Martinez MJ, Gil P: Gastrointestinal bezoars: sonographic and CT characteristics. Am J Roentgenol 200I, 177:65-69.

6. Walker-Renard P: Update on the medicinal management of phytobezoars. Am J Gastroenterol 1993, 88:1663-1666.

\section{Do you have a case to share?}

Submit your case report today

- Rapid peer review

- Fast publication

- PubMed indexing

- Inclusion in Cases Database

Any patient, any case, can teach us something

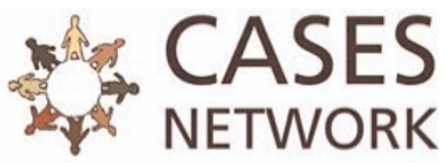

www.casesnetwork.com 